\title{
Field Evaluation of Concrete using Hawaiian Aggregates for Alkali Silica Reaction
}

\author{
Ian Robertson ${ }^{1, *}$, and Lin Shen ${ }^{1}$ \\ ${ }^{1}$ University of Hawaii, Dept. of Civil and Environmental Engineering, 2540 Dole Street, Honolulu, Hawaii, 96822, USA
}

\begin{abstract}
Alkali Silica Reaction (ASR) occurs in concrete when the alkali hydroxides $\left(\mathrm{Na}^{+}, \mathrm{K}^{+}\right.$and $\mathrm{OH}^{-}$) from the cement react with unstable silica, $\mathrm{SiO}_{2}$, in some types of aggregate. The resulting gel will expand when it absorbs water, potentially leading to cracking and overall expansion of the concrete. Concrete aggregates available in Hawaii have not demonstrated a history of ASR, however, results of accelerated laboratory tests using ASTM C1260 indicated a potential for ASR with some aggregates. In order to assess the accuracy of the laboratory test results, a long-term field study of the potential for ASR in concretes made with Hawaiian aggregates was initiated in 2011. Forty concrete specimens were constructed of various concrete mixtures using aggregates from all Hawaiian aggregate sources, and some US mainland aggregates known to exhibit ASR expansion. The specimens are located in an open field site in Manoa valley on the Hawaiian Island of Oahu, exposed to relatively high humidity and frequent rainfall. A weather station at the site records the ambient conditions on a continual basis. This paper describes the field evaluation program and presents the results after six years of monitoring. Comparisons are made between the field observations and accelerated laboratory tests.
\end{abstract}

\section{Introduction}

Alkali Silica Reaction, ASR, was first discovered in the early 1930's by Thomas Stanton [1]. He made the initial discovery in concrete pavement in California. Stanton's early laboratory work demonstrated that expansion and cracking resulted when certain combinations of high alkali cement and aggregate were combined in mortar bars and stored in very high relative humidity. From his work, two important conclusions were drawn and still hold true today. First, expansion resulting from ASR was negligible when alkali levels in the cement were less than $0.60 \%$. Second, was that the partial replacement of high alkali cement with a suitable pozzolanic material prevents excessive expansion within the concrete [1]. Both are methods still employed today as mitigation techniques for ASR.

ASR is a reaction where hydroxyl ions $\left(\mathrm{OH}^{-}\right)$in the alkaline cement pore solution and free reactive silica in aggregate forms a gel (Fig. 1). The gel can increases in volume by absorbing water resulting in internal pressure within the concrete. This can lead to cracking and premature failure of the concrete. The expansive alkali silica gel will not swell if water is not available in the concrete.

In 2003 the floor covering of a large concrete slabon-grade at the Tripler Army Medical center on Oahu, Hawaii, was failing. Core samples were sent to two laboratories for evaluation. Both laboratories reported potential ASR in the concrete. This was the first recorded indication of potential ASR in concrete utilizing Hawaiian aggregates. As a result, a test program was initiated by University of Texas and University of New Brunswick, Canada, funded by the Federal Highway Administration (FHWA), to establish a field site on Oahu to evaluate the potential for ASR when using local Hawaiian aggregates [2].

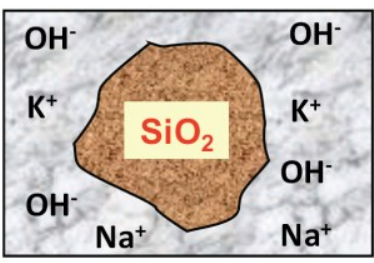

Reaction between the alkali hydroxide (Na, K \& OH) from the cement and unstable silica, $\mathrm{SiO}_{2}$, in some types of aggregate.

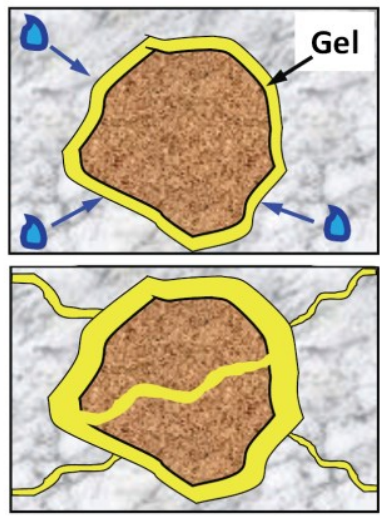

The reaction produces an alkali-silica gel.

The gel absorbs water from the surrounding paste ...

Fig. 1. Sequence of ASR from FHWA-HIF-12-022 [3]

\footnotetext{
* Corresponding author: ianrob@hawaii.edu
} 


\section{Aggregate Properties}

"Local" basaltic aggregates from six different quarries located on the Hawaiian Islands were included in the study. Coarse aggregate and manufactured sand were available from each source. Imported siliceous sand (Orca) from British Columbia in Canada was also used as this sand has been used by some Hawaiian concrete producers. The seven Hawaiian aggregate sources are listed in Table 1.

In order to verify that the field exposure conditions were suitable to produce ASR, aggregates known to experience ASR were imported from three mainland US sources, listed in Table 2. These aggregates were used in seven of the field specimens along with Hawaiian aggregates and high-alkali cement.

For most of the specimens, the water-tocementitious-materials ratio was $\mathrm{w} / \mathrm{cm}=0.42$, and the coarse-to-fine aggregate ratio was $\mathrm{C} / \mathrm{F}=60 / 40$. The dosage of high-range water-reducing admixture, HRWA was adjusted for each batch to provide suitable workability. Most specimens used a high-alkali cement with $1.20 \% \mathrm{Na}_{2} \mathrm{Oe}$ while others used cement with alkali as low as $0.55 \% \mathrm{Na}_{2} \mathrm{Oe}$. Lithium nitrate $\left(\mathrm{LiNO}_{3}\right)$ and/or Fly Ash were added to selected mixtures as these admixtures are known to suppress ASR. Full details of the material properties and mix designs for each of the 40 field specimens are provided in [2].

\section{Laboratory Tests}

ASTM C1260 and ASTM C1293 are common accelerated laboratory tests to determine whether or not ASR is a concern for a particular aggregate source. The ASTM C1260 protocol involves fabrication of a mortar bar using crushed aggregate from the source. The mortar bars are submerged in a high-alkali solution (1M of $\mathrm{NaOH})$ at $80^{\circ} \mathrm{C}$ for 14 days. If the specimen expansion is less than $0.1 \%$, then the aggregate is assumed to be nonreactive. If the specimen expansion exceeds $0.2 \%$, there is potential that the aggregate is reactive. For expansion between $0.1 \%$ and $0.2 \%$ the results are inconclusive. This is a very aggressive test which has been criticized because it may classify good aggregates as reactive (false positive).

The ASTM C1293 protocol involves fabricating a concrete prism using the test aggregate and high-alkali cement. The prism is maintained in a $100 \%$ humidity environment at $38^{\circ} \mathrm{C}$ for one year. If the specimen expansion exceeds $0.04 \%$ then the aggregate is considered susceptible to ASR.

Typical project specifications require that the ASTM C1260 test be performed first. If the resulting expansion is below $0.1 \%$ then the aggregate is assumed not to be reactive and can be used for construction. If the expansion exceeds $0.1 \%$, then the ASTM C1293 test should be performed to preclude a false positive result. If the aggregate fails the ASTM C1293 test, it should not be used for construction without taking measures to mitigate the potential for ASR. Possible mitigation measures include using low-alkali cement and including
Fly Ash and/or Lithium Nitrate in the mixture. The proposed mitigation measures should be tested using ASTM C1293 to ensure they are effective.

All of the Hawaiian aggregates used in this study were tested at the University of Texas, Austin [2], and at the University of Hawaii at Mano. Table 1 shows the expansion data from the accelerated mortar-bar test (AMBT), ASTM C1260, and concrete prism test (CPT), ASTM C 1293.

The imported reactive mainland US aggregates used in this study were tested at the University of Texas, Austin [2]. Table 2 shows the expansion data from the accelerated mortar-bar test (AMBT), ASTM C1260, and concrete prism test (CPT), ASTM C 1293 for these aggregates.

The accelerated laboratory tests indicate that all three of the imported US mainland aggregates are indeed reactive according to both the ASTM C1260 and C1293 tests. A number of the Hawaiian aggregates indicate potential ASR based on the ASTM C1260 test, but only one, from the Waikoloa quarry on Hawaii Island, is clearly reactive based on the ASTM C1293 test. It would appear that the majority of ASTM C1260 reactive results are false positives.

Table 1. "Local" Hawaiian aggregate laboratory results

\begin{tabular}{|c|c|c|}
\hline Source & $\begin{array}{c}\mathrm{AMBT}^{1} \text { at } \\
14 \text { days } \\
(\%) \\
\end{array}$ & $\begin{array}{c}\mathrm{CPT}^{2} \text { after } 1 \\
\text { year at } 38^{\circ} \mathrm{C} \\
(\%)\end{array}$ \\
\hline \multicolumn{3}{|c|}{ Coarse Aggregates } \\
\hline Kapaa, Oahu & $\begin{array}{c}0.084 * \\
0.060 * *\end{array}$ & $\begin{array}{l}-0.003^{*} \\
0.040^{* *}\end{array}$ \\
\hline Halawa, Oahu & $\begin{array}{c}0.627^{*} \\
0.130^{* *}\end{array}$ & $\begin{array}{l}0.003 * \\
0.02 * *\end{array}$ \\
\hline Hilo, Hawaii & $0.633 *$ & - \\
\hline Waimea, Hawaii & $0.015 *$ & - \\
\hline \multicolumn{3}{|c|}{ Fine Aggregates } \\
\hline Kapaa, Oahu & $\begin{array}{c}0.076^{*} \\
0.050^{* *}\end{array}$ & $0.004 *$ \\
\hline Halawa, Oahu & $\begin{array}{c}0.526 * \\
0.260^{* *}\end{array}$ & $0.019^{*}$ \\
\hline Hilo, Hawaii & $0.718^{*}$ & $0.029 *$ \\
\hline Waimea, Hawaii & $0.007^{*}$ & - \\
\hline Waikoloa, Hawaii & $\begin{array}{c}0.522 * \\
0.253 * *\end{array}$ & $\begin{array}{c}0.287 * \\
0.038 * *\end{array}$ \\
\hline Maui Dune Sand & $\begin{array}{c}0.015 * \\
0.035 * *\end{array}$ & $0.011^{*}$ \\
\hline Orca (BC, Canada) & $\begin{array}{c}0.222 * \\
0.090 * *\end{array}$ & $0.003^{*}$ \\
\hline Halfway Bridge, Kauai & - & $0.018^{*}$ \\
\hline \multicolumn{3}{|c|}{$\begin{array}{l}{ }^{1} \text { AMBT = Accelerated Mortar-Bar Test, ASTM C1260 } \\
{ }^{2} \text { CPT = Concrete Prism Test, ASTM C1293 } \\
\text { * Test performed at University of Texas, Austin [2] } \\
\text { ** Test performed at University of Hawaii at Manoa } \\
\text { Shaded cells indicate that the test results exceed the } \\
\text { threshold for deleterious expansion indicative of ASR. }\end{array}$} \\
\hline
\end{tabular}


Table 2. Imported US mainland reactive aggregate laboratory results

\begin{tabular}{|c|c|c|}
\hline Source & $\begin{array}{c}\mathrm{AMBT}^{1} \text { at } \\
14 \text { days } \\
(\%)\end{array}$ & $\begin{array}{c}\mathrm{CPT}^{2} \text { after } \\
1 \text { year at } \\
38^{\circ} \mathrm{C}(\%)\end{array}$ \\
\hline \multicolumn{3}{|c|}{ Coarse Aggregates } \\
\hline Placitas, New Mexico & 0.820 & 0.159 \\
\hline \multicolumn{3}{|c|}{ Fine Aggregates } \\
\hline Jobe, Texas & 0.640 & 0.582 \\
\hline Wright, Texas & 0.290 & 0.270 \\
\hline \multicolumn{3}{|c|}{$\begin{array}{l}{ }^{1} \text { AMBT }=\text { Accelerated Mortar-Bar Test, ASTM } \\
\text { C1260 } \\
{ }^{2} \text { CPT = Concrete Prism Test, ASTM C1293 } \\
\text { All tests performed at University of Texas, Austin. } \\
\text { Shaded cells indicate that the test results exceed the } \\
\text { threshold for deleterious expansion indicative of ASR. }\end{array}$} \\
\hline
\end{tabular}

\section{Field Exposure Site}

In 2011, 30 concrete blocks were cast using various concrete mixtures incorporating both Hawaiian aggregates and Mainland US aggregates known to experience ASR. These specimens were placed at a field exposure site in Manoa Valley on the island of Oahu as shown in Fig. 2 and 3. The specimens are monitored on a regular basis using a high-precision digital strain gage (Fig. 4 and 5).

After one and a half years of monitoring, one of the specimens with local aggregate from the Waikoloa quarry on Hawaii Island showed signs of expansion. This confirmed the observations from the accelerated laboratory tests presented earlier. Therefore, 10 additional specimens were fabricated in 2013 using the Waikoloa aggregate, some with mitigation measures, and added to the field site.

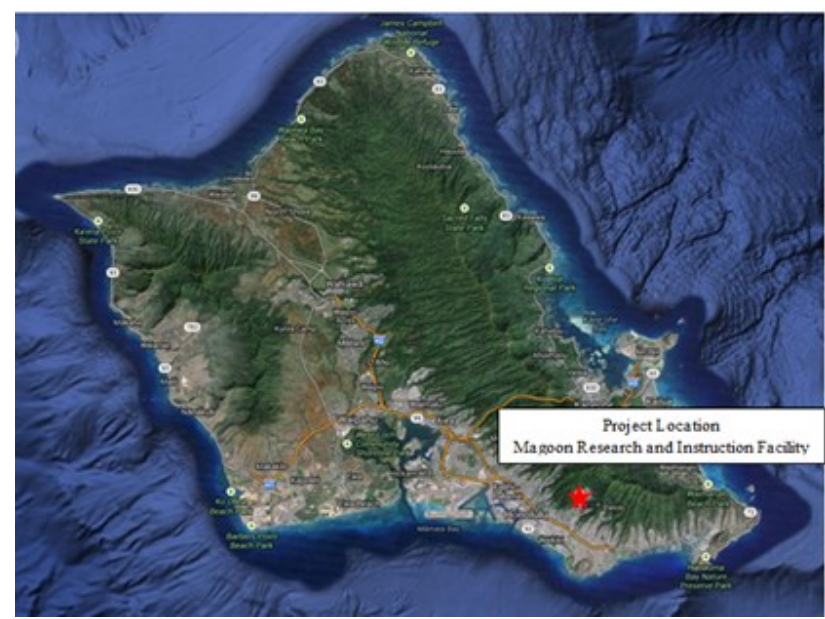

Fig. 2. ASR field site location on Oahu

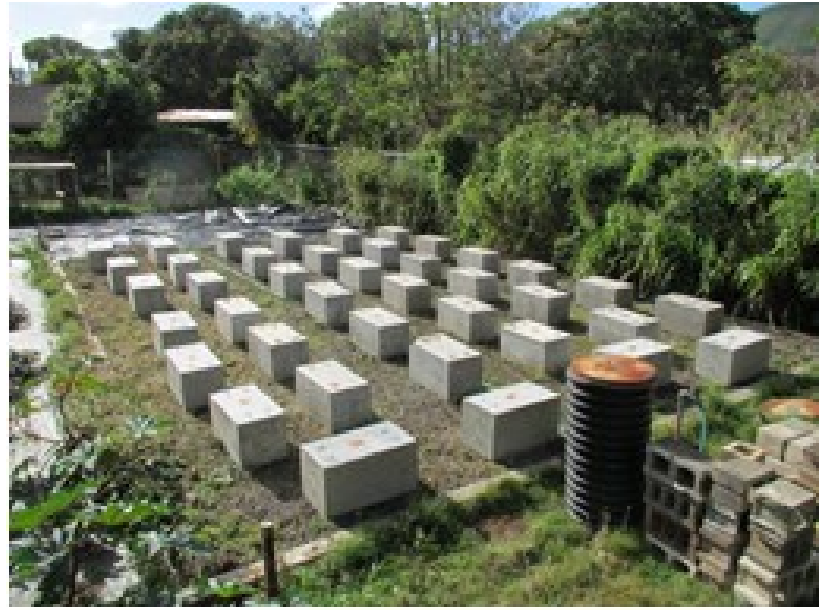

Fig. 3. ASR field specimens

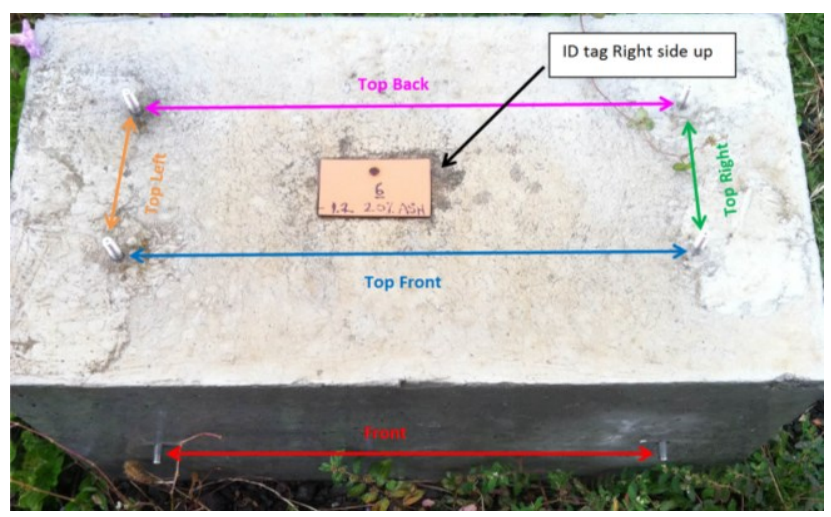

Fig. 4. High-precision length measurements

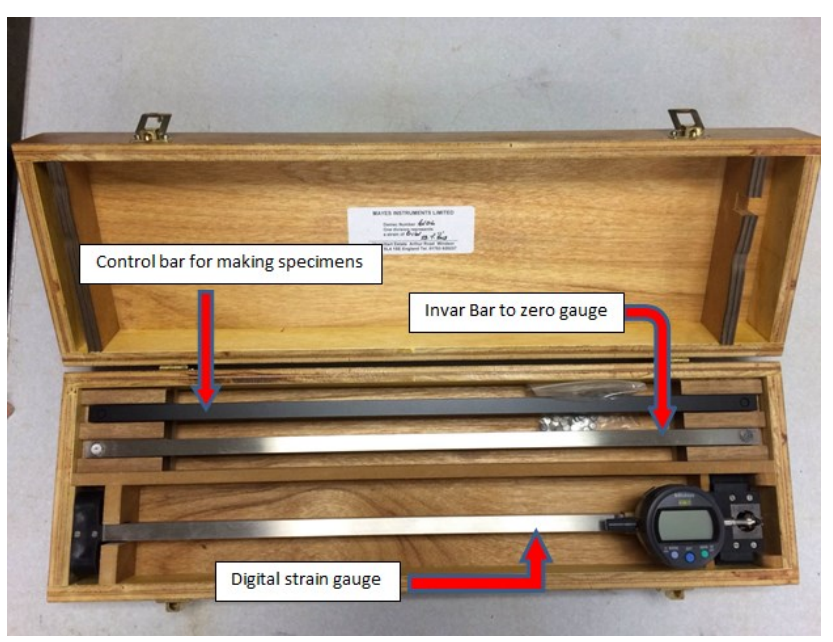

Fig. 5. High-precision digital strain gage

A weather station at the field site records ambient temperature, relative humidity and rainfall. This location has a high relative humidity (Fig. 6) and frequent rainfall (Fig. 7), ensuring that there is ample moisture to induce swelling of ASR gel if it is present in the concrete. 


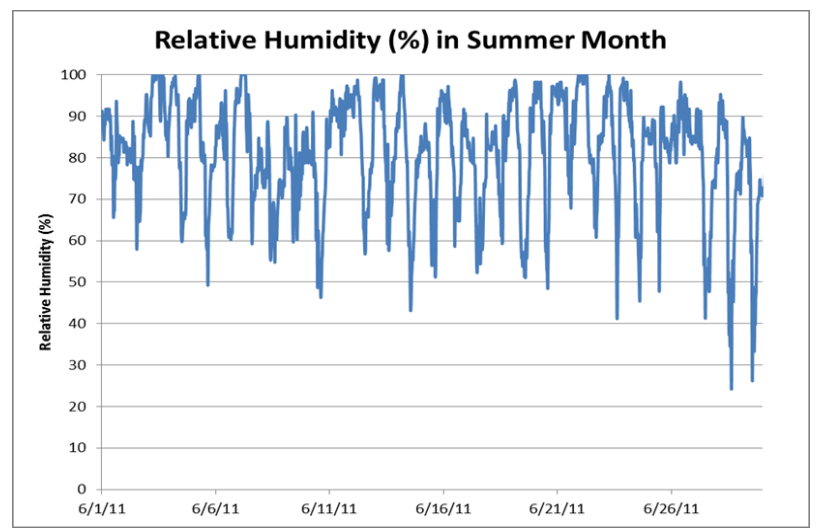

Fig. 6. Relative humidity during typical Summer month

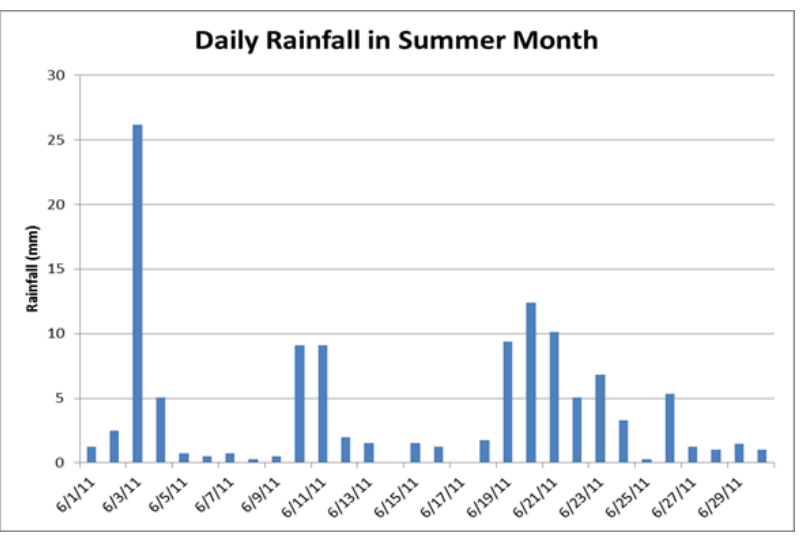

Fig. 7. Rainfall during typical Summer month

\section{Field Specimen Results}

Seven of the field specimens contain some form of Mainland US aggregate that is known to exhibit ASR. The results for these specimens are plotted in Fig. 8. Three of the seven specimens exhibited rapid expansion for the first year of exposure, quickly exceeding the $0.04 \%$ expansion considered to represent deleterious behaviour. The expansion of one of these specimens appears to have reached a limit while the other two continue to expand. The remaining four specimens show no signs of expansion due to ASR, with all readings remaining below the $0.04 \%$ limit for all 6 years of monitoring.

Fig. 9 shows typical ASR cracking observed on the top surface of one of the specimens exhibiting high expansion.

There are two major aggregate sources on the island of Oahu, namely Halawa Quarry and Kapaa Quarry. There are smaller aggregate sources elsewhere on Oahu and on the other Hawaiian Islands. Fig. 10 shows the results for all of the specimens fabricated with aggregate from the Halawa Quarry, while Fig. 11 shows the results for all of the specimens fabricated with aggregate from the Kapaa Quarry and other quarries around the Hawaiian Islands.

None of these specimens has exceeded the $0.04 \%$ threshold, so it can be concluded that none of these aggregates exhibits ASR after 6 years of exposure.

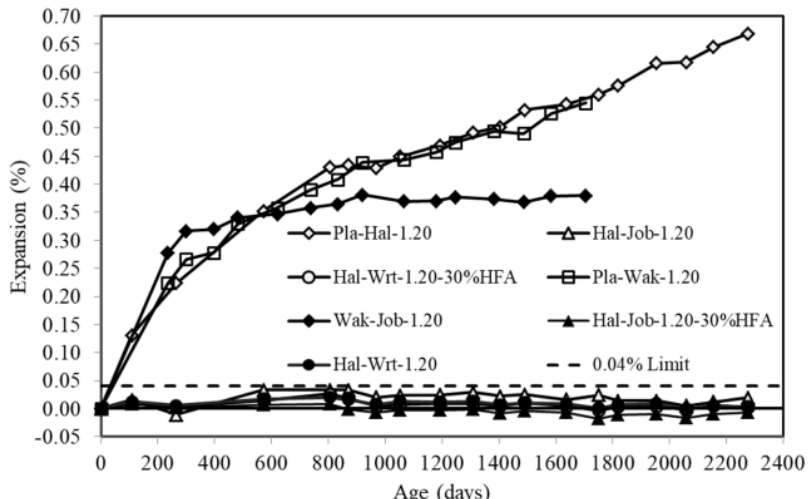

Fig. 8. Expansion measurements for field specimens containing aggregates known to exhibit ASR.

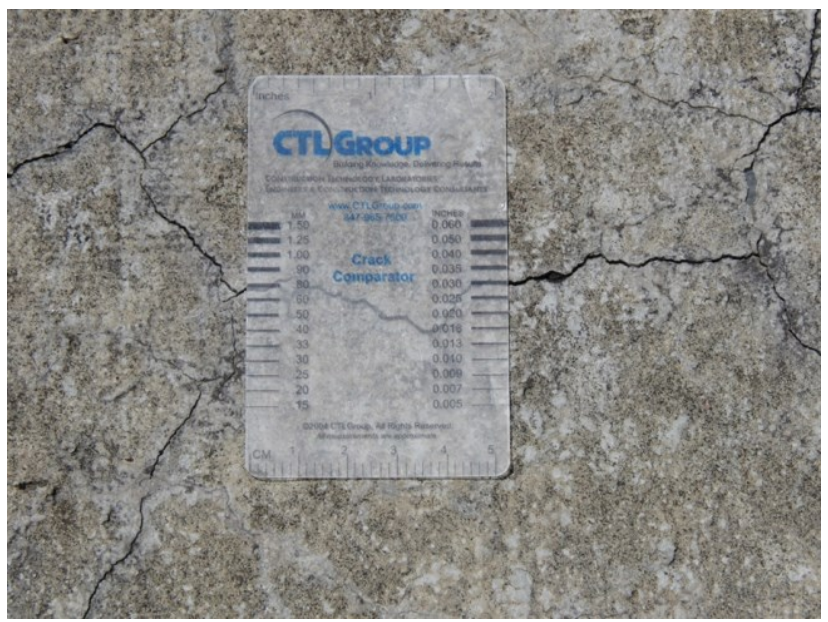

Fig. 9. Cracking on top surface of field specimen exhibiting ASR induced expansion.

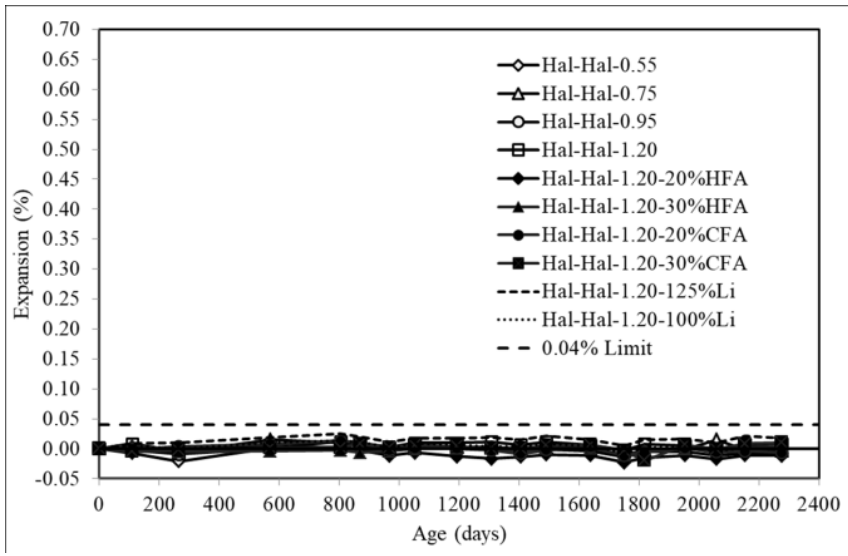

Fig. 10. Expansion measurements of field specimens made with aggregates from the Halawa Quarry.

However, one specimen made with aggregates from Waikoloa Quarry on Hawaii Island exhibited greater expansion than any of the others (Figs. 12, 13 and 14). Accelerated laboratory tests of this aggregate also indicated potential for ASR reaction. As a result, 10 more specimens were fabricated with this same aggregate and placed at the field site approximately one and a half years after the original specimens. One of these new specimens was identical to the original, while others contained cement with varying levels of alkalinity, Lithium Nitrate and Fly Ash, both of which 
are known to reduce the potential for ASR. Fig. 12 shows that the initial specimen with Waikoloa aggregate has continued to expand, exceeding the $0.04 \%$ threshold after 3 years, and is currently at $0.35 \%$ expansion on an upward trend. None of the 10 additional specimens show any signs of expansion even after 4.5 years exposure, including one that was nominally identical to the original specimen.

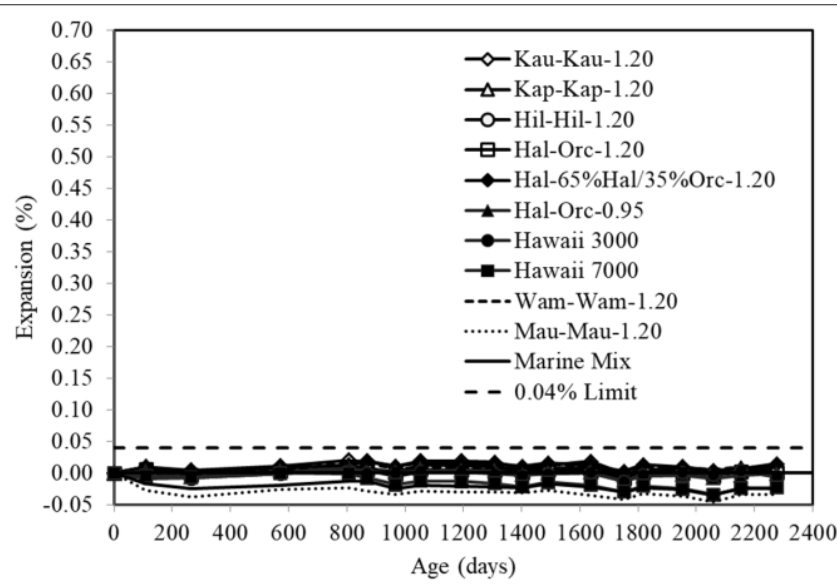

Fig. 11. Expansion measurements of field specimens made with aggregates from the Kapaa and other quarries in the Hawaiian Islands.

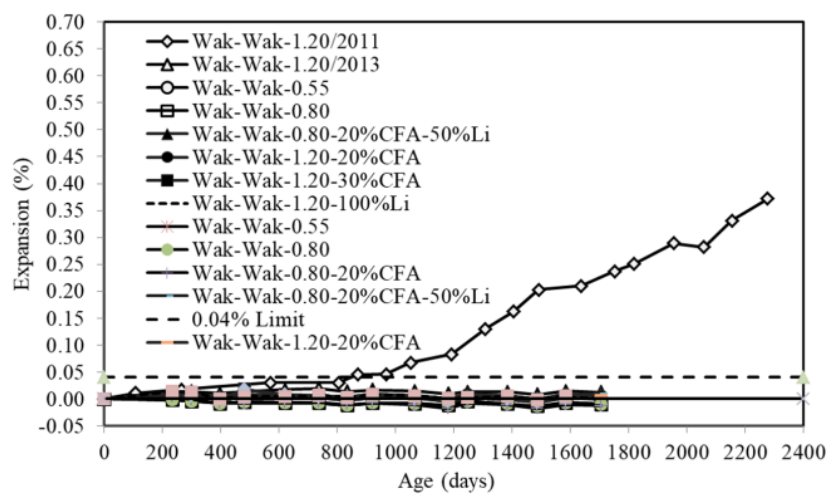

Fig. 12. Expansion measurements of field specimens made with aggregates from the Waikoloa Quarry.

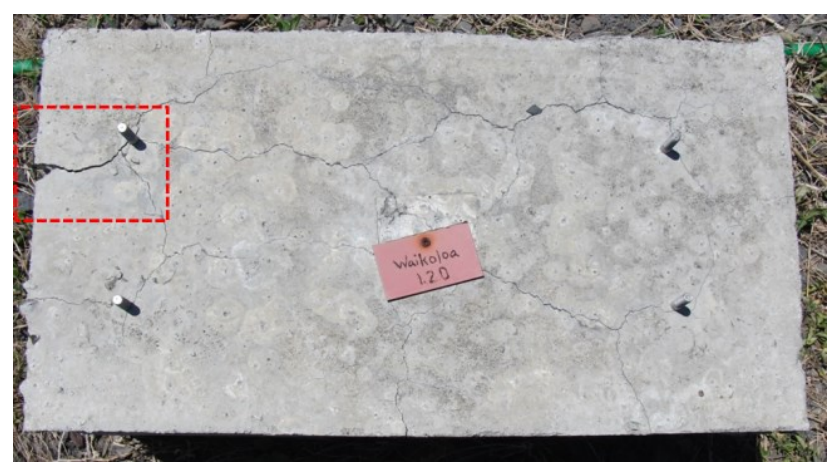

Fig. 13. Cracks on top surface of Waikoloa specimen experiencing ASR induced expansion.

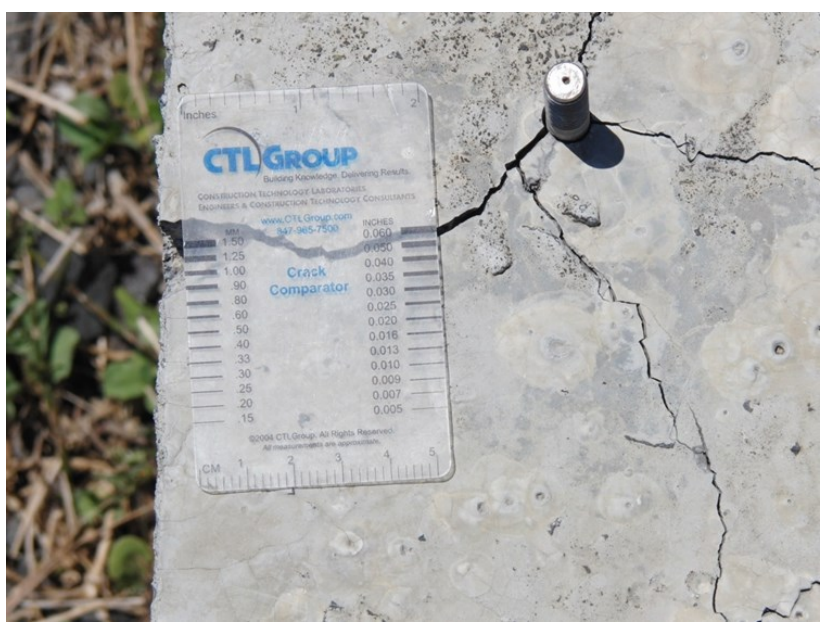

Fig. 14. Detail of cracks on Waikoloa specimen.

\section{Summary and Conclusions}

A study was performed to assess the potential for Alkali Silica Reaction (ASR) in concrete fabricated using aggregates from a number of Hawaiian quarries. Two different accelerated laboratory tests were performed as well as an extended duration field study. The 14-day ASTM C1260 laboratory test resulted in a number of false positives, while the 1-year ASTM C1293 laboratory test indicated that one of the Hawaiian quarries produced aggregate that could potentially suffer from ASR.

Forty large field specimens were fabricated and exposed to ambient humidity and rainfall at a field site on Oahu. The specimen fabricated with the Hawaiian aggregate that failed the ASTM C1293 laboratory test showed signs of ASR in the field study. However, none of the other Hawaiian aggregates have shown any signs of expansion or cracking due to ASR even after field exposure for 6 years.

Based on the results of this study, the following conclusions are drawn:

- The ASTM C1260 accelerated laboratory test for ASR is not a reliable indicator of the potential for ASR. Specimens that pass this test can be assumed not to suffer from ASR. However, specimens that fail this test do not necessarily experience ASR under field exposure conditions. The test should not be relied on as the only indicator of the potential for ASR.

- The ASTM C1293 accelerated laboratory test for ASR is a more reliable indicator of the potential for ASR. Specimens that fail this test also performed poorly under field exposure conditions.

- Based on the high expansion of field specimens containing US mainland aggregates known to suffer from ASR, it was confirmed that the ambient conditions at the Oahu field site are indeed severe enough to promote ASR if the expansive gel is present in the concrete.

- Only one of the Hawaiian quarry aggregates experienced ASR expansion and cracking in the field study. Aggregate from this quarry is not 
currently used for concrete manufacture, and it is recommended that it not be used in the future without a validated mitigation measure.

- Field specimens fabricated with aggregate from all of the other Hawaiian Island Quarries showed no signs of ASR after 6 years of exposure at the field site.

The authors wish to acknowledge the financial support received from the Federal Highway Administration and Hawaii Department of Transportation to support this project. Thanks are also extended to Kevin Folliard, Michael Thomas and Benoit Fournier who initiated the study. Student assistants Jacob McKamey and Reza Mirmoghtadaei are thanked for their work on the field site and laboratory testing, respectively.

\section{References}

1. T.E. Stanton, "Expansion of concrete through reaction between cement and aggregate," Proceedings of the American Society of Civil Engineers, Vol. 66, No. 10, pp. 1781-1811 (1940)
2. Folliard, K.J., and Thomas, M.D.A., "Methods of Preventing ASR in New Construction: Results of Field Exposure Sites", Project Report to FHWA, pp. 13 (2013)

3. FHWA, "Alkali-Silica Reactivity Field Identification Handbook", Report No. FHWA-HIF12-022, pp. 80 (2011)

4. ASTM C1260-07. "Standard Test Method for Potential Alkali Reactivity of Aggregates (MortarBar Method).” ASTM C1260, ASTM International, West Conshohocken, PA, 5 p (2007)

5. ASTM C1293-08. "Standard Test Method for Determination of Length Change of Concrete Due to Alkali-Silica Reaction." ASTM C1293, ASTM International, West Conshohocken, PA, 7 p (2008) 